
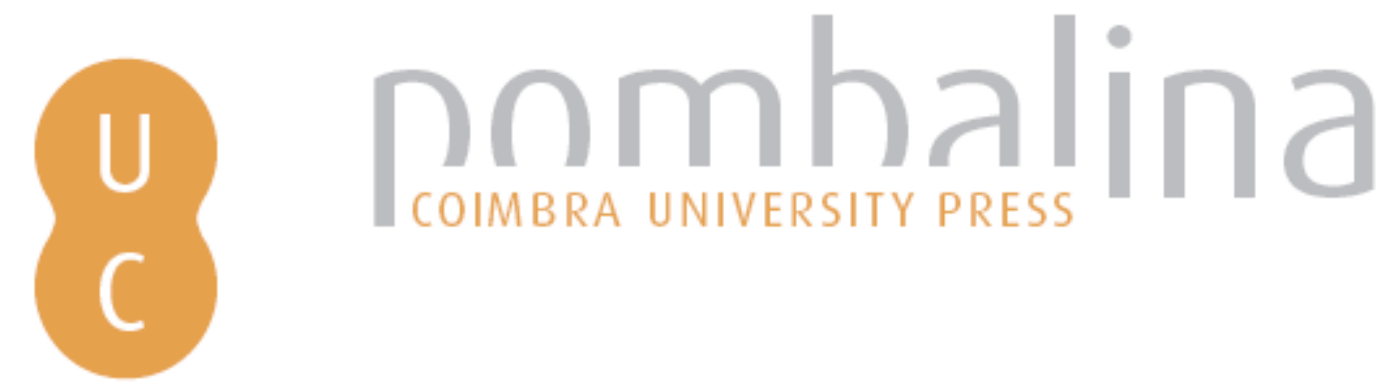

\title{
O cruzeiro do Sul na cartografia celeste dos séculos XVI e XVII: evidências cartográficas ajudam a derrubar um mito
}

\author{
Autor(es): $\quad$ Silva, Gil Alves
}

Publicado por: Imprensa da Universidade de Coimbra

URL

persistente: URI:http://hdl.handle.net/10316.2/38437

DOI: $\quad$ DOI:http://dx.doi.org/10.14195/978-989-26-0764-1_1

Accessed : $\quad$ 26-Apr-2023 14:05:01

A navegação consulta e descarregamento dos títulos inseridos nas Bibliotecas Digitais UC Digitalis, UC Pombalina e UC Impactum, pressupõem a aceitação plena e sem reservas dos Termos e Condições de Uso destas Bibliotecas Digitais, disponíveis em https://digitalis.uc.pt/pt-pt/termos.

Conforme exposto nos referidos Termos e Condições de Uso, o descarregamento de títulos de acesso restrito requer uma licença válida de autorização devendo o utilizador aceder ao(s) documento(s) a partir de um endereço de IP da instituição detentora da supramencionada licença.

Ao utilizador é apenas permitido o descarregamento para uso pessoal, pelo que o emprego do(s) título(s) descarregado(s) para outro fim, designadamente comercial, carece de autorização do respetivo autor ou editor da obra.

Na medida em que todas as obras da UC Digitalis se encontram protegidas pelo Código do Direito de Autor e Direitos Conexos e demais legislação aplicável, toda a cópia, parcial ou total, deste documento, nos casos em que é legalmente admitida, deverá conter ou fazer-se acompanhar por este aviso.

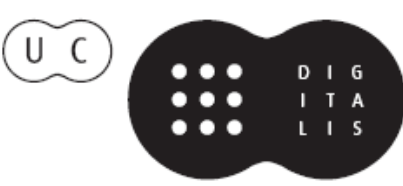


Grupo de História das Ciências e das Tecnologias e Epistemologia - Universidade Federal do Rio de Janeiro gilalvessilva@yahoo.com.br

\section{O CRUZEIRO DO SUL NA CARTOGRAFIA CELESTE DOS SÉCULOS XVI E XVII: EVIDÊNCIAS CARTOGRÁFICAS AJUDAM A DERRUBAR UM MITO}

\section{Gil Alves Silva}

Dos documentos relacionados ao descobrimento do Brasil, a carta de Mestre João é o primeiro e mais importante de natureza astronômica. Astrônomo, cartógrafo e médico da frota, Mestre João fora incumbido pelo rei D. Manuel de descobrir - por meio da observação dos astros - em que latitude se encontrava a terra em que aportaram. Para realizar a tarefa ele recorreu ao Regimento de Munique (manual para a determinação da latitude a partir da observação da altura do Sol), embora também tentasse encontrar a "estrela do polo antártico" (como chamou a estrela com pouco movimento ao redor do polo celeste), pois sua altura acima do horizonte revelaria a latitude do lugar. $\mathrm{Na}$ busca pela Polar do sul, Mestre João fornece um esboço das adjacências do polo celeste, descrevendo e retratando um grupo de estrelas que ele chamou de Cruz (possivelmente a primeira referência ao Cruzeiro do Sul, embora algumas dessas estrelas fossem conhecidas desde a antiguidade como parte da constelação do Centauro).

Conquanto o Cruzeiro fosse mencionado por navegantes que tentavam a sorte ao sul do equador, ainda são encontradas referências que relacionam sua criação, nomeação ou desmembramento do Centauro ao cartógrafo francês Augustin Royer em 1679 (vide notas ao final do texto), mesmo que quase dois séculos antes fossem achadas representaçôes de uma cruz em planisférios e globos celestes - tornando insustentável o mito de Royer. O objetivo deste trabalho é verificar como a cartografia celeste dos séculos XVI e XVII consolidou o Cruzeiro do Sul como constelação separada do Centauro, não nos ocupando, entretanto, de tentar explicar ou entender a origem desse mito.

\section{Metodologia}

Nesse exercício de desmistificação vamos utilizar apenas registros visuais encontrados em mapas e globos celestes. Pela impossibilidade de reprodução de todas as imagens pesquisadas, selecionamos um conjunto que acreditamos retratar bem o período estudado e as informações e créditos de cada uma estão em suas respectivas legendas (imagens usadas aqui com fins puramente didáticos). Embora não haja dificuldades para localizar o Cruzeiro, ele sempre aparecerá envolto por um círculo vermelho. A disposição das figuras segue uma ordem cronológica dividida em dois 
períodos: representações de uma cruz celeste no século XVI (figuras 1 a 6) e no século XVII (fiuras 7 a 12). Essa forma de apresentação acabou se mostrando bastante proveitosa na análise feita ao final deste artigo.

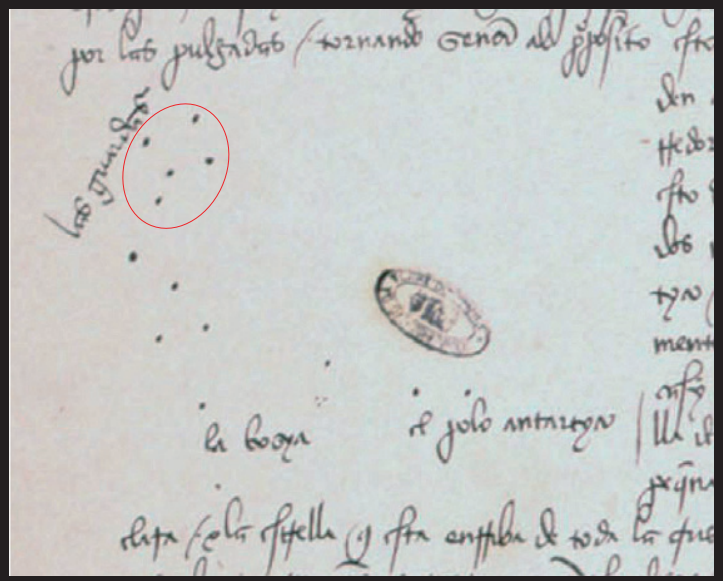

Figura 1. Carta de Mestre João ao Rei D. Manuel (1500)ํ․

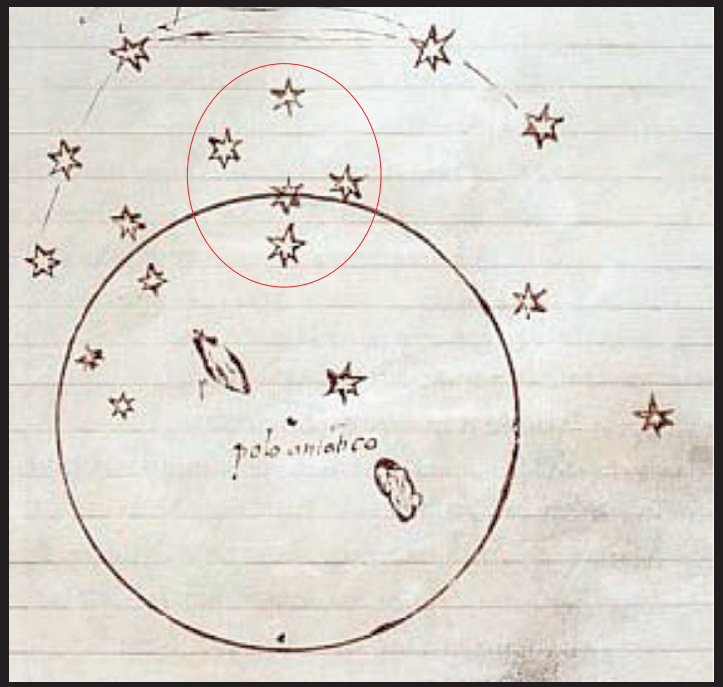

Figura 2. Carta enviada por Andrea Corsali ao duque Juliano de Médici, de 6 de janeiro de $1515^{2}$.

${ }^{1}$ Documento cedido pelo ANTT. Título: Carta de Mestre João a D. Manuel I sobre o Cruzeiro do Sul. Cota actual: Corpo Cronológico, Parte 3, maço 2, nº 2 .

${ }^{2}$ Cortesia de Kevin Leamon da State Library of New South Wales. Bruce \& Joy Reid Foundation. Mitchell Library, Sydney - Safe 1 /239. Fonte: http://nationaltreasures.nla.gov.au 


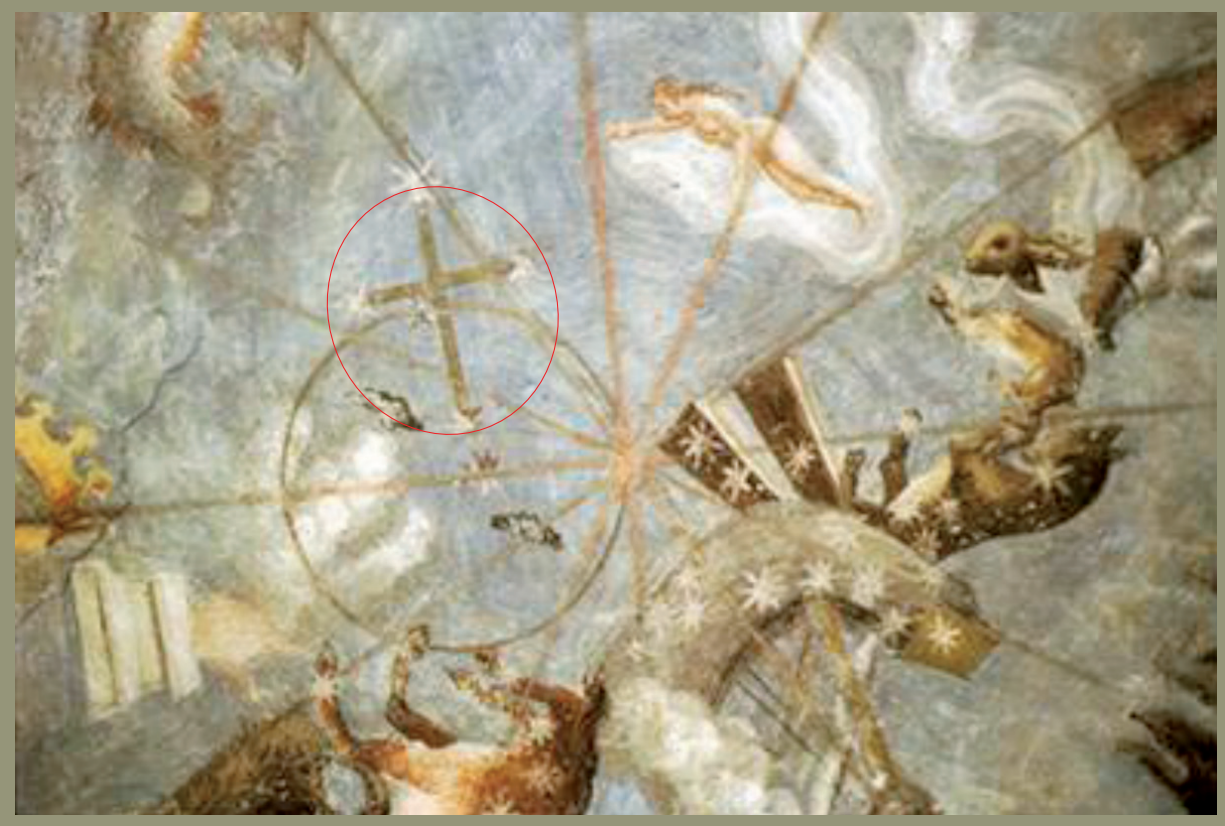

Figura 3. La creazione del cielo, anônimo (ca. 1550).

Fonte: http://www.atlascoelestis.com/1.htm

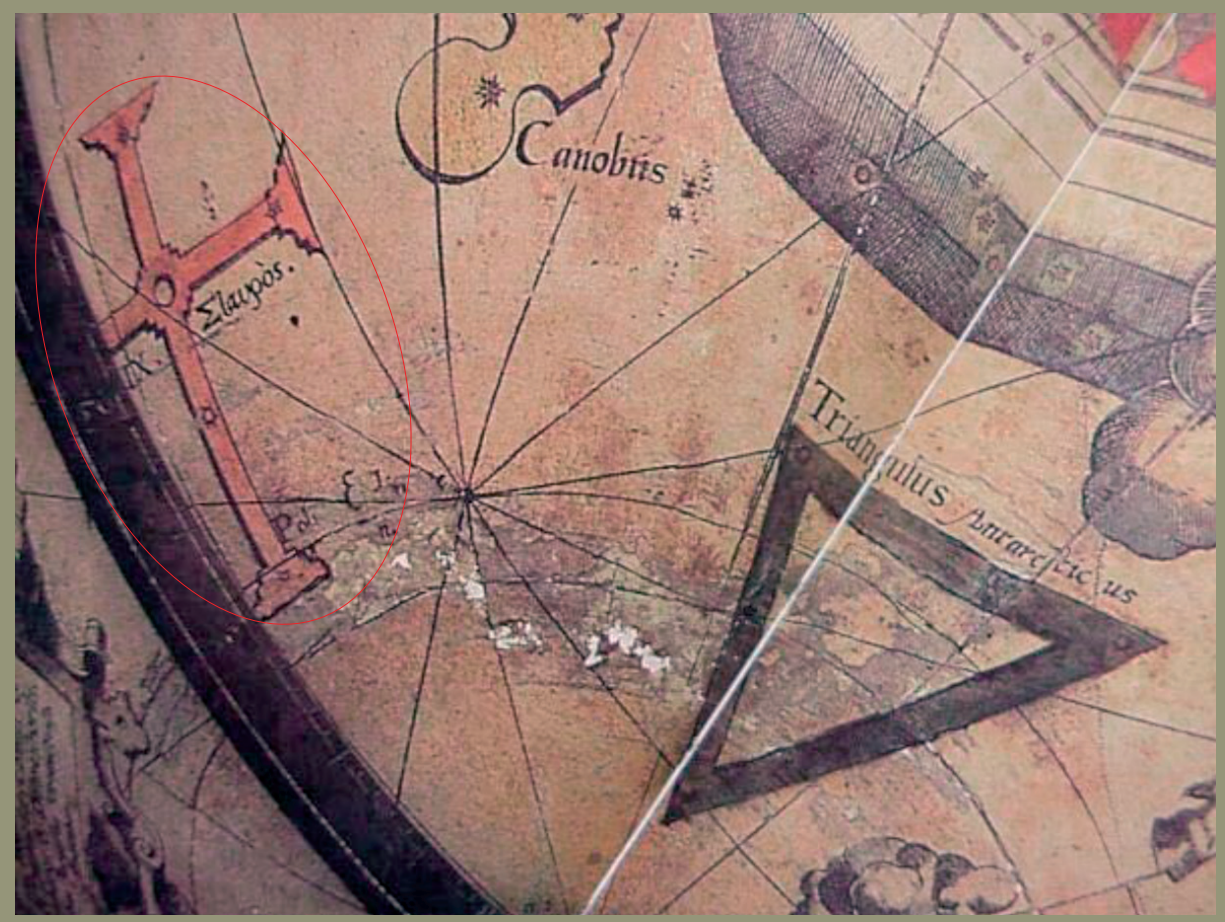

Figura 4. Globo celeste desenhado por Jacob e Arnold Van Langren e publicado por Petrus Plancius (1589). Fonte: http://pavoobs.hu/index.php?page=pavo 


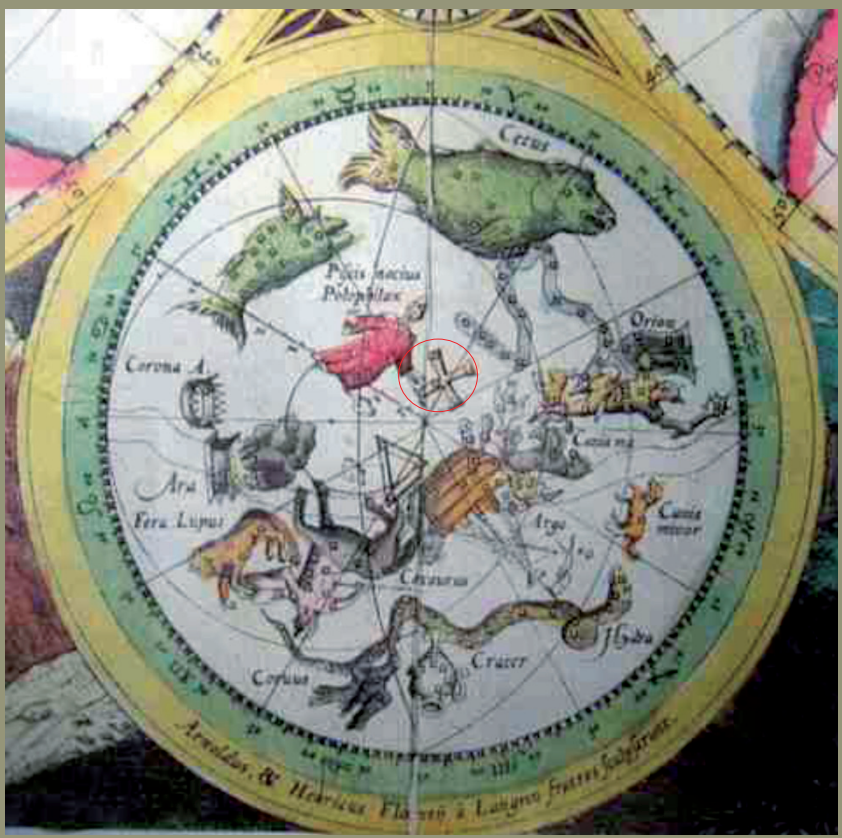

Figura 5. Hemisfério sul de Cornelius Claesz (1592).

Fonte: http://pavoobs.hu/index.php?page=pavo

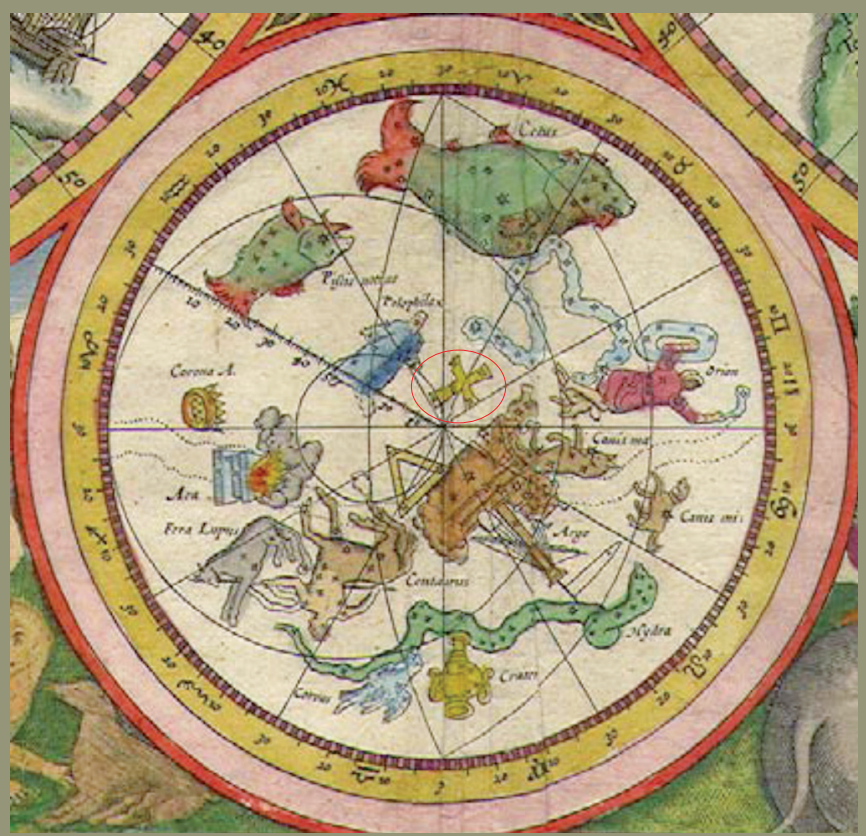

Figura 6. Hemisfério sul de Petrus Plancius (1594).

Fonte:http://www.ianridpath.com/startales/polophylax.htm 


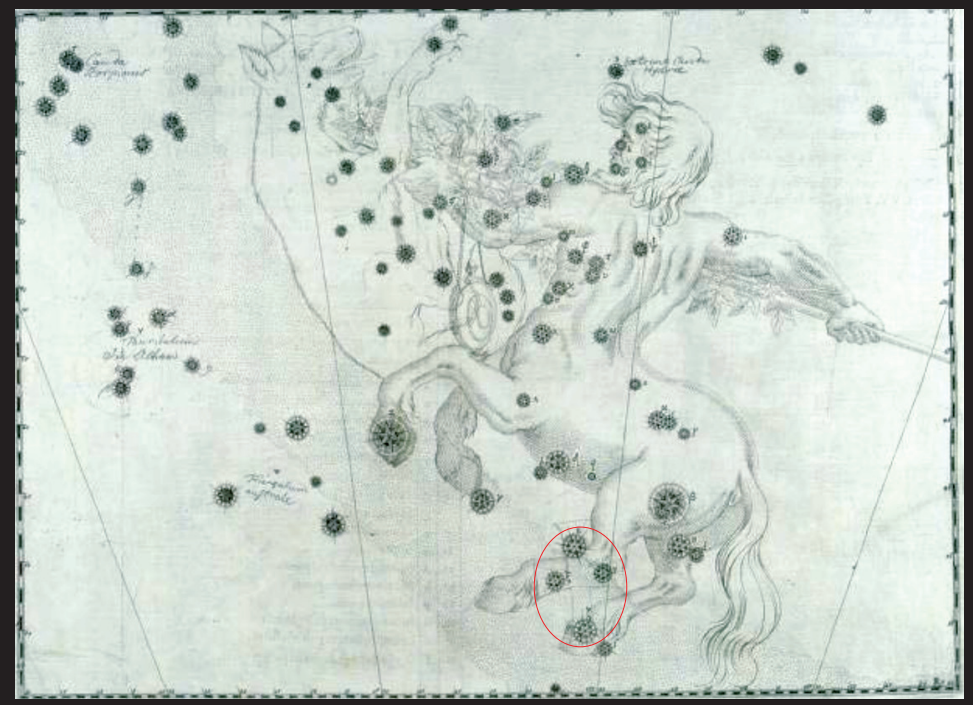

Figura 7. Uranometria (1603), de Johann Bayer. Fonte: http://lhldigital.lindahall.org

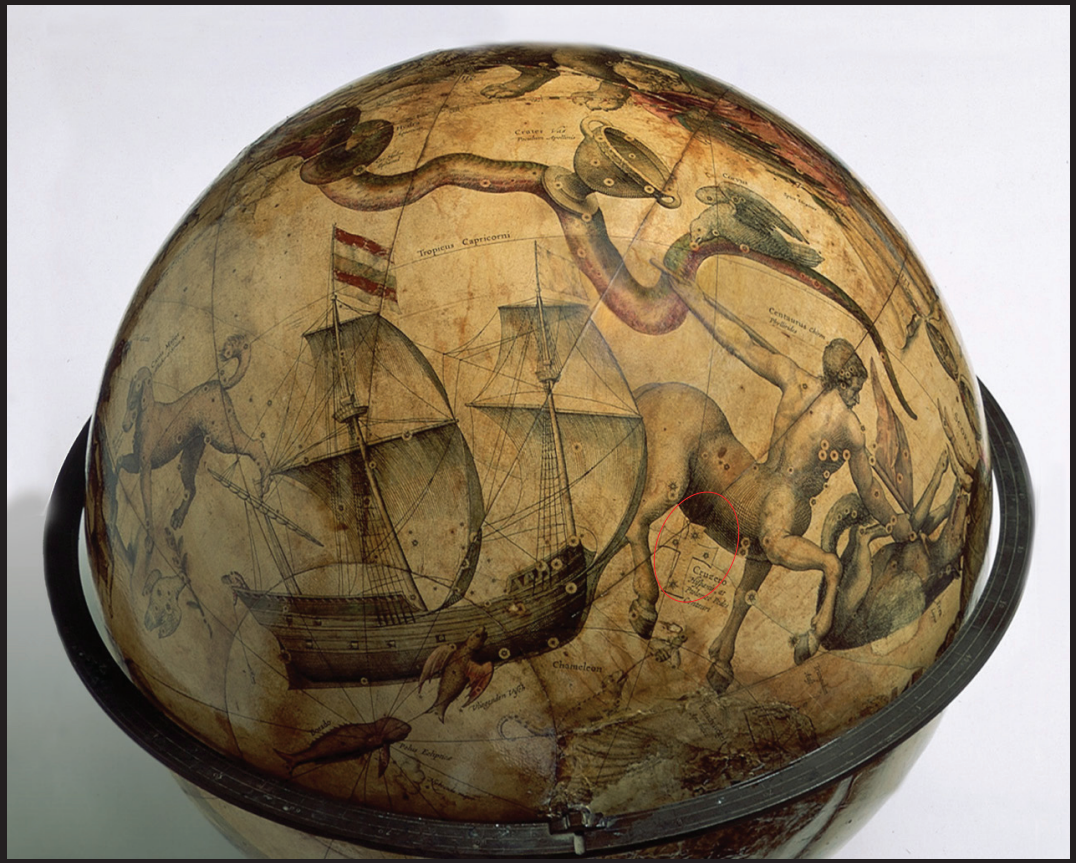

Figura 8. Globo celeste de Jodocus Hondius Jr. (1613). ${ }^{3}$

${ }_{3}^{3}$ Fonte: Royal Museums Greenwich. http://collections.rmg.co.uk/collections/objects/19809.html. 


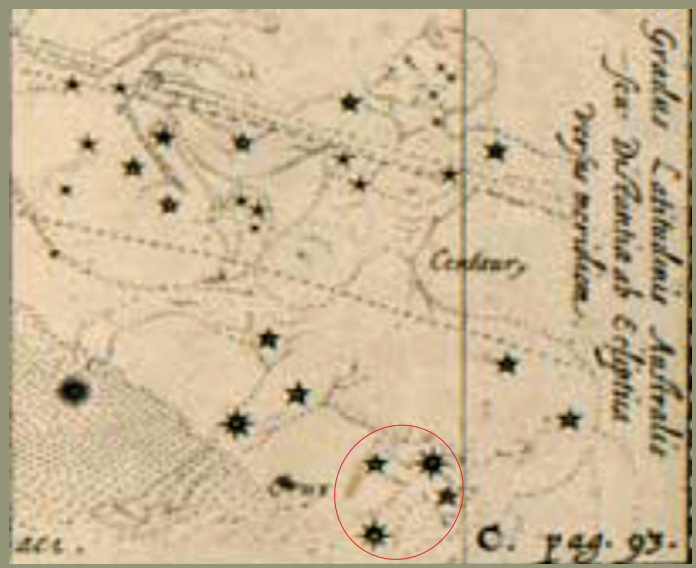

Figura 9. Planisphaerum Stellatum (1624), de Jacob Bartsch. Fonte: http://www.atlascoelestis.com/Bartsch.htm

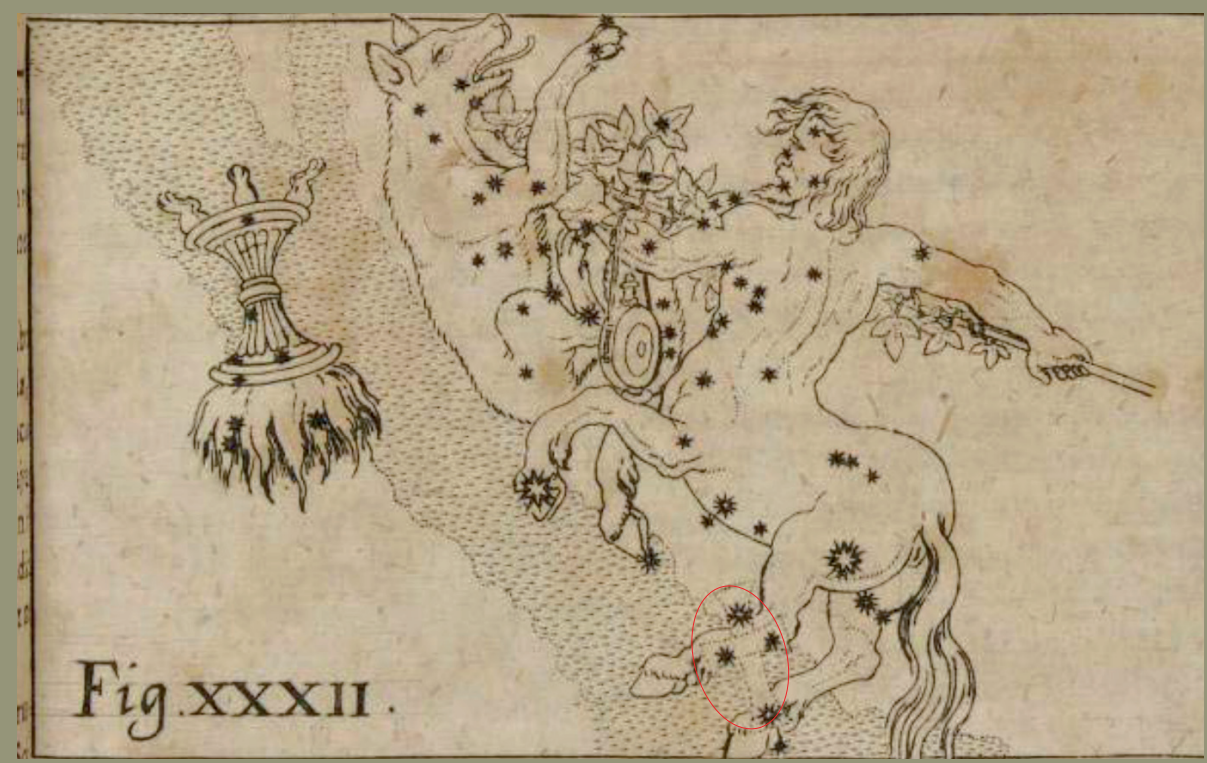

Figura 10. Astrognosia (1659), de Aegidii Strauch. Fonte: http://lhldigital.lindahall.org 


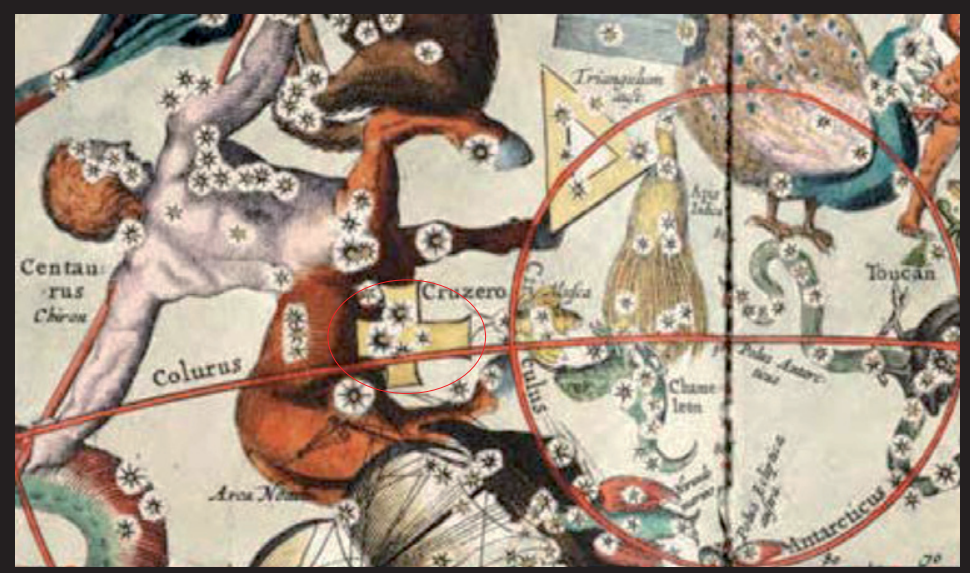

Figura 11. Harmonia Macrocosmica (1661), de Andreas Cellarius. Fonte: http://lhldigital.lindahall.org

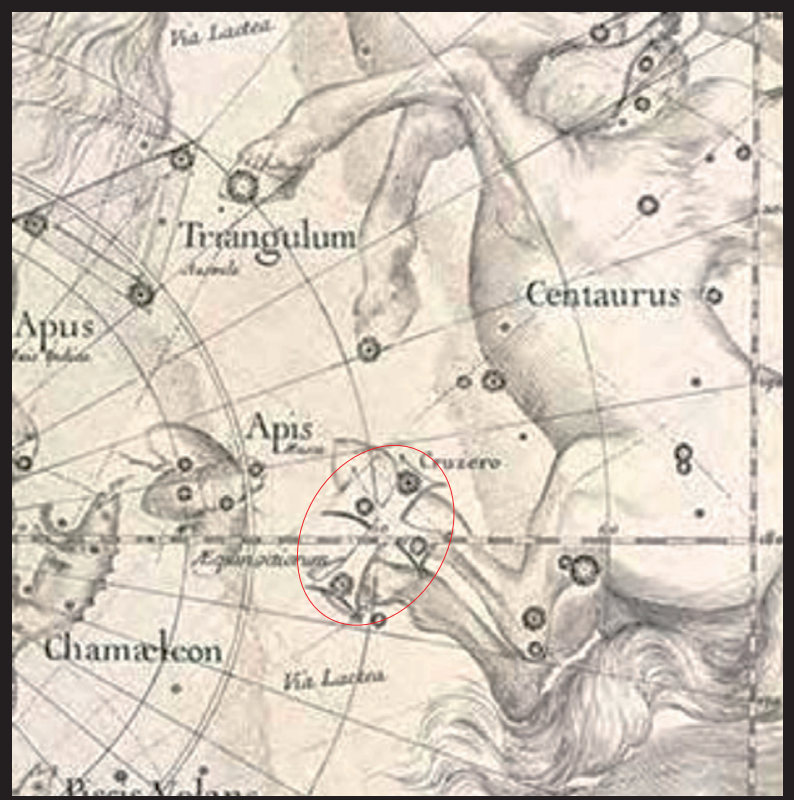

Figura 12. Globi Coelestis (1674), de Ignace Pardies. Fonte: http://lhldigital.lindahall.org 


\section{Resultados}

Na carta que enviou ao monarca português, Mestre João reproduziu o polo celeste e suas adjacências, inclusive um grupo de estrelas em forma de cruz. Embora careça de constelações vizinhas e orientação espacial mais apurada, a missiva originada em solo brasileiro parece ter sido o pontapé inicial para todo um movimento quinhentista de descrição e representação do Cruzeiro do Sul, revelando o caráter pioneiro desse documento.

O esboço do céu que consta na carta de Corsali funcionou como outro grande difusor do Cruzeiro do Sul entre os europeus. Diferente do croqui de Mestre João, aqui as estrelas que formam a haste vertical da Cruz estão alinhadas com o polo antártico - assinalado como um ponto para diferenciá-lo das 17 estrelas retratadas e das Nuvens de Magalhães. Embora também não represente constelações à volta, Corsali desenhou um círculo, mostrando que as estrelas do Cruzeiro giram em torno do polo a uma distância de $30^{\circ}$.

Ao longo do século XVI a cartografia passou a retratar novos elementos balizadores (sistemas de coordenadas, círculos principais, Via-Láctea, constelações adjacentes e outros), facilitando o posicionamento da Cruz nos mapas. Os hemisférios celestes, por exemplo, foram divididos em 12 partes - relacionadas às constelações zodiacais - e tiveram as bordas seccionadas em graus. Na figura 3 o Cruzeiro aparece acompanhado das Nuvens de Magalhães e do Círculo Polar Antártico, enquanto as figuras 4, 5 e 6 vêm acrescidas do Equador Celeste, do Trópico de Capricórnio e da Via-Láctea.

Fazendo um balanço da primeira metade de nossa amostra verificamos que ela é composta por representaçôes do Cruzeiro do Sul onde ainda faltam elementos que comprovem sua autenticidade (figuras 1 e 2) ou na qual ele está localizado numa posição completamente diferente da que conhecemos (figuras 3, 4, 5 e 6).

As figuras 7 a 12 mostram representações onde o Cruzeiro do Sul está localizado corretamente, e podem ser divididas em duas categorias: uma em que ele está sobre as patas traseiras do Centauro (figuras 7, 10 e 12) e outra na qual está logo abaixo do seu ventre (figuras 8,9 e 11 ).

Nosso levantamento iconográfico confirmou a suspeita de que não existe um pioneirismo de Royer em relação ao Cruzeiro do Sul. Os mapas e globos consultados revelaram que ele:

1 - não criou, inventou ou introduziu o Cruzeiro na cartografia celeste (exploradores europeus já haviam descrito ou retratado uma cruz celeste no século XVI);

2- não nomeou o Cruzeiro (antes dele estas estrelas já eram chamadas de Crux, Cruz, Croce, Cruzeiro ou Cruzero) nem expandiu seu nome para Crux Australis;

3- não separou ou desmembrou o Cruzeiro do Centauro.

A discussão em torno do mito até perde a razão de ser quando nos deparamos com a figura 13, na qual vemos que Royer não representou o Cruzeiro separado do Centauro, além de não utilizar a terminação Australis após a palavra Crux. 


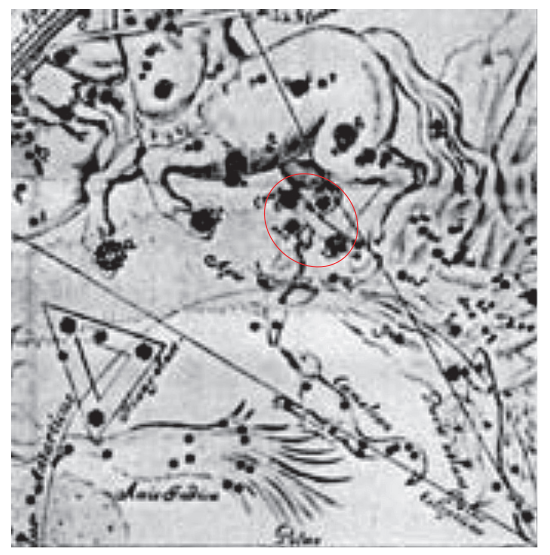

Figura 13. Cartes du Ciel (1679), de Augustin Royer.

Fonte: http://pavoobs.hu/index.php?page=pavo

\section{Consideraçốes Finais}

A pesquisa parece ter encontrado evidências cartográficas suficientes para desconstruir o mito de Royer (ironicamente ele parece ter sido seu próprio algoz). Nosso trabalho identificou claramente dois períodos distintos de representação do Cruzeiro do Sul: enquanto no século XVI a escassez de dados e o excesso de descrições resultaram numa localização errônea, no século XVII sua posição já estava consolidada: a única dúvida era se a Cruz seria retratada sobre as patas traseiras ou abaixo do ventre do Centauro.

O trabalho também mostrou que a cartografia celeste do século XVI evoluiu no sentido de agregar novos elementos aos mapas, de forma que a Cruz pôde ser localizada mais facilmente. Esses novos elementos, entretanto, acabaram revelando que o Cruzeiro retratado não estava em sua localização atual - entrave superado somente com as explorações holandesas do final do século, que viabilizaram seu posicionamento correto e ajudaram a perpetuar sua representação na cartografia vindoura.

\section{NOTAS}

VIEIRA, Fernando. 1999. Identificação do céu. Rio de Janeiro: Fundação Planetário (p. 30).

"Adicionada por Royer (1679): Cruzeiro do Sul: Crux. Embora oficialmente seja Royer o criador desta constelação, bem antes dele ela já era conhecida com este nome pelos navegantes".

KANAS, Nick. 2007. Star Maps: History, Artistry, and Cartography. Chichester: Springer Praxis Books (p. 160).

"Royer was the first person to show the Southern Cross as a distinct constellation in a star map".

ALLEN, Richard Hinckley. 1963. Star names: their lore and meaning. New York: Dover (p. 185).

"It's invention as a constellation is often atributted to Royer as of $1679 . . . "$

MOURÃO, Ronaldo Rogério de Freitas. 2000. A Astronomia na época dos descobrimentos. Rio de Janeiro: Lacerda Editores (p. 168).

“em 1679 Royer introduz a constelação do Cruzeiro do Sul descoberta por Mestre João...".

http://www.instituto-camoes.pt/revista/bandrnavegant.htm. Acesso em 21 de outubro de 2007.

“...Julius Staal...diz que teria sido o astrónomo francês Augustin Royer o primeiro a definir, em 1679, os seus contornos". 
http://www.asterdomus.com.br/Artigo_crux_australis.htm. Acesso em 18 de julho de 2008.

"O estabelecimento do nome Crux Australis... só veio com... Augustim Royer, em 1617, que separou as estrelas do Cruzeiro, definitivamente, do Centauro".

http://www.zenite.nu Acesso em 1 de março de 2011.

"Em 1697...Augustin Royer...desmembrou a Crux Australis da constelação do Centauro e a partir daí surgiu nas cartas celestes, oficialmente, a constelação do Cruzeiro do Sul".

http://nationaltreasures.nla.gov.au/\%3E/Treasures/item/nla.int-ex6-s29 Acesso em 1 de março de 2011.

"French astronomer, Royer, officially named the constellation 'Crux' in 1679".

http://www.oocities.org/edovila/astro/SouthernCross.html Acesso em 19 de maio de 2011.

"In 1671 the French Astronomer Augustine Royer expanded its name to Crux Australis".

http://www.southerncape.co.za/geography/astronomy/crux.php. Acesso em 24 de maio de 2011.

"Credit is given to the French astronomer Augustin Royer for defining it as a separate constellation and naming it Crux Australis in 1679".

\section{REFERÊNCIAS:}

ALLEN, Richard Hinckley - Star names : their lore and meaning. New York: Dover, 1963.

KANAS, Nick - Star Maps: History, Artistry, and Cartography. Chichester: Springer Praxis Books, 2007.

MOURÃO, Ronaldo Rogério de Freitas - A Astronomia na época dos descobrimentos. Rio de Janeiro: Lacerda, 2000.

MOURÃO, Ronaldo Rogério de Freitas - Dicionário Enciclopédico de Astronomia e Astronáutica. Rio de Janeiro: Nova Fronteira, 1995.

PEREIRA, Paulo Roberto - Os três únicos testemunhos do descobrimento do Brasil. Rio de Janeiro: Lacerda, 1999. STOTT, Carole - Cartas Celestes: antigos mapas do céu. Lisboa: Dinalivro, 1991.

VIEIRA, Fernando - Identificação do céu. Rio de Janeiro: Fundação Planetário, 1999.

\section{PÁGINAS WEB:}

http.://www.instituto-camoes.pt/revista/bandrnavegant.htm. Acesso em 21 de outubro de 2007. http://www.asterdomus.com.br/Artigo_crux_australis.htm. Acesso em 18 de julho de 2008. http://www.zenite.nu. Acesso em 1 de março de 2011.

http://nationaltreasures.nla.gov.au/\%3E/Treasures/item/nla.int-ex6-s29. Acesso em 1 de março de 2011. http://www.oocities.org/edovila/astro/SouthernCross.html. Acesso em 19 maio 2011.

http://www.ianridpath.com/startales/crux.htm. Acesso em 19 de maio de 2011. http://www.southerncape.co.za/geography/astronomy/crux.php. Acesso em 24 de maio de 2011. 